\title{
Sixty-second Denver X-ray Conference and selected papers for the special June Powder Diffraction issue
}

This issue of Powder Diffraction is comprised of selected papers presented at the 2013 62nd Annual Denver X-ray Conference (DXC). At DXC 16 workshops, 2 poster sessions, a plenary session The 100th Anniversary of X-ray Spectroscopy and 13 special sessions were held, covering the following topics:

New Developments in XRD \& XRF Instrumentation, Applications of XRD \& XRF in the Petroleum Industry, Applied Materials Analysis, High Energy XRD, Stress Analysis, Pair Distribution Function, Polymers, New Developments in Rietveld Analysis, Quantitative Analysis, Applications for Portable XRF, Fusion \& Industrial Applications of XRF, Micro XRF, and Trace Analysis.

As part of the Denver Conference, proceedings are published and from these proceedings, select papers covering XRD, XRF, and other high-energy scattering methods were selected for publication in Powder Diffraction. This issue of Powder Diffraction will provide readers with the opportunity to learn about current topics in a variety of materials characterization applications.
The talents of many people are required to make this special issue possible. Besides the authors themselves, we thank the DXC organizing committee members for their reviews of these articles. We would also like to thank the DXC conference coordinator Denise Zulli and Powder Diffraction managing editor Nicole Ernst Boris for all of their hard work in making this publication a reality. We hope you enjoy this compilation of manuscripts and we look forward to seeing you at the 2014 Denver X-ray Conference in Big Sky, Montana, 28 July-1 August, 2014 (www. dxcicdd.com).

Tom Blanton

International Centre for Diffraction Data

George Havrilla

Los Alamos National Laboratory

Co-editors in Chief, Advances in X-ray Analysis 